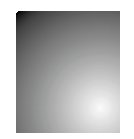

\title{
Empreendedorismo Religioso: quando Weber SE ASSOCIA A Granovetter
}

\section{Religious Entrepreneurship: when Weber joins the Granovetter}

\section{Victor Silva Corrêa}

Doutor em administração pela Pontifícia Universidade Católica de Minas Gerais. Belo Horizonte, MG. Brasil. E-mail:

victorsilvacorrea@yahoo.com.br

\section{Glaucia Maria Vasconcellos Vale}

Professora Adjunta do Mestrado e Doutorado e Mestrado/Fundação Dom Cabral/PUC Minas. Pontifícia Universidade Católica de Minas Gerais (PUC-MG). Belo Horizonte, MG. Brasil.E-mail: galvale@terra.com.br

\section{Marina Almeida Cruz}

Doutoranda em Administração pela Universidade Federal de Minas Gerais - UFMG. Belo Horizonte, MG. Brasil.

E-mail: marina.almeida.cruz@gmail.com

\section{Resumo}

O fenômeno religioso no Brasil vem atraindo crescente atenção da academia, impulsionado, em grande parte, pela expansão das seitas protestantes no país, sobretudo de vertente pentecostal. Na esteira dessa transformação, um tema, em particular, reveste-se de especial importância. Trata-se do papel dos chamados empreendedores religiosos aqui compreendidos como os novos pastores evangélicos. No entanto, tais atores não vêm sendo muito estudados. O presente trabalho busca preencher essa lacuna. Recorre-se, para isso, às contribuições teóricas clássicas derivadas de Weber, em associação às contribuições contemporâneas originárias de Granovetter, em particular, sobre acoplamento e desacoplamento. Conclui-se o trabalho propondo um novo referencial para a análise de certas dimensões do empreendedorismo religioso.

Palavras-chave: Acoplamento. Desacoplamento. Redes Sociais. Empreendedor. Religião.

\section{Abstract}

The religious phenomenon in Brazil is attracting increasing attention from academia, driven largely by the growth of Protestant sects in the country, particularly Pentecostal strand. Following this transformation, a theme in particular is of special importance. It is the role of so-called religious entrepreneurs, here understood as the new evangelical pastors. However, these actors have not been much studied. This paper seeks to fill this gap. Uses for this, the theoretical contributions derived from Weber, in association with contemporary contributions originating from Granovetter, in particular, coupling and decoupling. Concludes by proposing a new framework for the analysis of certain religious dimensions of entrepreneurship.

Keywords: Coupling. Decoupling. Social Networks. Entrepreneur. Religion. 


\section{INTRODUÇÃO}

O Brasil vem presenciando, nas últimas décadas, uma crescente conversão de fiéis, originários, sobretudo, do catolicismo, para religiões de natureza neopentecostal. Um dos responsáveis por esse processo é o próprio agente religioso - os pastores evangélicos - reconhecido por adotar um comportamento ativo, agressivo e competitivo, de arregimentação de novos fieis e de defesa dos interesses de suas igrejas, fazendo jus à designação de empreendedores religiosos - sobre tal tema, ver Correa e Vale (2016) e Mariano (2015). Muitos dos pastores são, por sua vez, também originários de outras comunidades religiosas, em geral católicas.

Ao ingressarem no círculo evangélico, esses atores deixaram, muitas vezes, para trás, relações sociais, inclusive de natureza familiar, originárias do período pré-conversão. Esse relativo distanciamento das respectivas comunidades de origem - caracterizado por uma supressão ou arrefecimento de laços sociais mais antigos - em detrimento de laços sociais mais recentes, centrados nas novas comunidades religiosas, parece dotar esses atores não apenas de menor constrangimento como, também, de maior disposição $e$ autonomia para perseguir objetivos de evangelização, de interesse de suas congregações e igrejas.

Nesse contexto, o fenômeno emergente do ativismo religioso parece estar associados, entre outras dimensões, não apenas a um fenômeno de desacoplamento ou afrouxamento de laços anteriores como, também, de criação de novos laços, em uma comunidade afeta à nova religião de conversão. Tal tema remete-nos à literatura sobre redes sociais.

A literatura sobre as redes sociais passou, sobretudo a partir da década de 1980, a integrar um vasto e promissor campo de pesquisas sobre o empreendedorismo. Nesse contexto, o empreendedor é vislumbrado como ator imerso em uma rede de relações e como agente capaz de usufruir de diferentes recursos que aí circulam (GRANOVETTER, 1973; 1983; 1988; 1990; 1992a; 1992b; 2005a; 2005b; ALDRICH; ZIMMER, 1986; BIRLEY, 1986; BURT, 1980; 1999; 2008; UZZI, 1997; JOHANNISSON, 2000; CHELL, 2000; LECHNER; DOWLING; WELPE, 2006; MARTES, 2009; MARTINELLE, 2009;). Embora reflexões sobre tais temáticas tenham evoluído ao longo dos últimos anos, uma de suas possíveis vertentes, a que reflete sobre a dinâmica entre as redes sociais e as atividades empreendedoras de natureza fundamentalmente religiosa, em particular, não tem, no entanto, sido explorada em todas as suas potenciais possibilidades. Reconhecido como um dos segmentos profissionais de mais rápida expansão no país (PIERUCCI, 2011), o empreendedorismo religioso, reconhecem Serafim, Martes e Rodrigues (2012, p. 218), "[...] não vem recebendo a atenção necessária por parte da academia brasileira".

Isso porque, quando as redes sociais são inseridas em estudos de populações religiosas, elas geralmente são destinadas a análises comparativas entre certas comunidades protestantes e católicas - ver, por exemplo, Serafim, Martes e Rodrigues (2012). Por outro lado, quando a literatura ressalta a temática do empreendedorismo religioso, o foco volta-se principalmente para a investigação de como a secularização do Estado tem ainda hoje repercutido no acirramento concorrencial entre os agentes eclesiásticos, desconsiderando, dessa dinâmica, as implicações eventualmente derivadas das estruturas de relações sociais - ver, por exemplo, Warner (1993), Finke (1997), Iannaccone (1995; 1997), Stark, Iannaccone e Finke (1996), Stark (1999), Gracino Junior (2008), Mariano (2003; 2008), Pierucci (2000a; 2000b), Frigerio (2008), Rabuske et al. (2012). Estudos do tipo aqui implementado - que propõem reflexões teóricas sobre as redes sociais e, também, sobre o empreendedorismo religioso, incluindo ainda postulações teóricas resultantes da convergência entre ambas as abordagens -, são raramente encontrados na literatura, segundo levantamento realizado entre o período de 2008 e 2016. Neste último ano, destaca-se a excepcionalidade do artigo de Correa e Vale (2016) que, por sua vez, trata da temática das igrejas como empreendimentos no Brasil.

Este artigo, uma inovação na área, busca justamente contribuir para preencher parte dessa identificada lacuna de pesquisa. Baseado nas reflexões clássicas de Max Weber, associadas, ao mesmo tempo, às proposições contemporâneas de Mark Granovetter, propõe-se uma nova interpretação teórica, considerada possivelmente, capaz de ampliar a nossa compreensão sobre o fenômeno do empreendedorismo religioso em uma sociedade em franca transformação religiosa e sua associação à temática das redes sociais. 
A perspectiva metodológica do presente artigo baseou-se, por um lado, em uma análise comparada minuciosa das proposições teóricas dos dois autores principais, aqui enfocados, complementada pela busca, identificação e análise da literatura nas áreas correlatas, nos últimos anos (2008 a 2016). Nesse contexto, procedeu-se a uma verificação, em periódicos de vários campos de conhecimento, incluindo, na área da administração, BAR, RAC, RAE, RAUSP, O\&S, RDA, e em anais de eventos (EnANPAD e EGEPE), sobre o tema do empreendedorismo religioso e redes sociais. Observou-se uma escassez de literatura nessa área, levando-nos a avançar na presente reflexão.

Esse artigo encontra-se dividido em três partes. Na primeira, apresenta o referencial teórico, que enfoca o tema do empreendedorismo religioso e das redes sociais, à luz, respectivamente, de Weber e de Granovetter. Em seguida, propõe uma nova interpretação teórica derivada da combinação entre as proposições de ambos os autores. Finalmente, a conclusão consolida as principais análises e tece possíveis considerações de interesse para futuros trabalhos.

\section{Marco Teórico}

A capacidade empreendedora dos agentes religiosos parece evidente em igrejas, sobretudo de natureza neopentecostal. Como observado por Correa e Vale (2016, p. 8), a "[...] postura empreendedora de muitos líderes religiosos vem chamando a atenção de alguns analistas". Ao mesmo tempo, muitos dos novos pastores, inseridos em um contexto de grande transformação na composição religiosa da população, em geral, como é caso, atualmente, no Brasil, parecem ter abandonado suas religióes de origem - em geral, o catolicismo $-e$, junto com elas, seus relacionamentos prévios. Inseridos em uma nova comunidade religiosa, parecem ser dotados de uma grande capacidade de interação e de criação de novas relações sociais, afetas à nova prática religiosa. Nesse contexto, afloram duas vertentes teóricas de interesse. A primeira, clássica, remete aos estudos de Weber sobre a inter-relação entre as doutrinas religiosas e o comportamento econômico (NERI, CARVALHAES, MONTE, 2011). Nesses estudos, o desempenho no contexto organizacional pode ser parcialmente compreendido como o resultado da influência exercida pelos ensinamentos religiosos ${ }^{1}$ na conduta de vida dos empreendedores. A segunda, por sua vez, alude às investigações contemporâneas inseridas no escopo da Nova Sociologia Econômica. Nelas, o empreendedor pode ser analisado como criador e articulador de redes e como agente no qual sua performance é influenciada pelo nível de acoplamento de seus agrupamentos sociais e pela natureza de suas relações diádicas.

\subsection{Perspectiva Clássica segundo Weber}

Essa perspectiva compreende o empreendedor a partir de uma abordagem ético-religiosa, na qual o seu comportamento e o seu desempenho no contexto organizacional são influenciados, em grande parte, pelas doutrinas religiosas de natureza protestante (BENDIX, 1986a; COHN, 1999; FREUND, 1983; KALBERG, 2010; SOUZA, 1999; WEBER, 1996 [1905]). Estão inseridas, nesta vertente de pesquisa, as reflexões associadas, sobretudo, a Max Weber (1996 [1905]). O autor publicou, em 1905, o livro mais famoso e controvertido (BAECHLER, 1995; BENDIX, 1986a; FREUND, 1983; 1987a; SCHLUCHTER, 1999; SELL, 2004) do conjunto de sua obra: A ética protestante e o espírito do capitalismo. Nessa obra, ele demonstrou como os ensinamentos religiosos puritanos originários dos séculos XVI e XVII influenciaram a conduta de vida da classe média a partir daquela época (BENDIX, 1986a; WEBER, 1996 [1905]) e estimularam entre os fiéis a adoção de uma conduta socioeconômica diretamente responsáveis por diferentes implicações. Duas delas são de particular importância para a presente pesquisa.

A primeira relaciona-se com o desempenho dos fiéis no segmento profissional. As doutrinas puritanas, argumentou Weber ([1905] 1996), passaram, sobretudo a partir do século XVI, por significativas modificações responsáveis por, em última instância, resultar na elaboração de novas premissas de natureza fundamentalmente religiosa. Uma das mais representativas delas refere-se especificamente à associação direta realizada pelos pastores da época entre o desempenho

1. Neste trabalho, compreende-se o fenômeno religioso como: i) o "[...] conjunto das práticas através das quais os homens procuram alcançar uma harmonia geral ou o apoio indulgente de forças favoráveis ao sucesso de seus empreendimentos" (BAECHLER, 1995, p. 451); ii) o "[...] impulso que impele o ser a superar sua condição humana para se abrir a algo, imanente ou transcendente, que o supera ao mesmo tempo em que o engloba." (BAECHLER, 1995, p. 452). 
profissional, por um lado, $e$ a salvação divina, por outro. A partir dessa correlação, os seguidores religiosos passaram a atribuir ao sucesso obtido nas diferentes atividades profissionais - dentre elas as empreendedoras -, um sinal claro de que Deus os escolhera para a vida eterna. "Hoje, nos parece um tanto difícil compreender por que essa questão preocupou tanto as pessoas. Mas, trata-se de um acontecimento histórico: os homens queriam saber quais eram as possibilidades de eles se salvarem" (SCHLUCHTER, 1999, p. 129). Para tanto, adotaram um ethos de planejamento e de busca estritamente racionalizada pelo sucesso profissional e pelo derivado lucro econômico (SELL, 2004).

Já a segunda implicação, esta de natureza essencialmente relacional, encontra-se diretamente associada com a primeira e se refere às seitas religiosas, compreendidas pelos fiéis como a estrutura adequada para assegurar entre eles o cumprimento dos comportamentos considerados moralmente adequados pelas doutrinas puritanas. Responsáveis por reunir os cristãos imbricados sob o mesmo estilo de vida e por, ao mesmo tempo, excluir aqueles não crentes das interações sociais de seus grupos (BENDIX, 1986a; SELL, 2004; WEBER, 1996 [1905]), as seitas puritanas - reconhecidas pelos rigorosos critérios de seleção fundamentados em atributos basicamente morais - desempenharam um dos mais importantes e poderosos instrumentos de controle social dos fieis e já eram, por si só, legitimadoras de seus valores de caráter. Com efeito, as seitas "[...] haviam sido um caso especial de associação voluntária entre pessoas que compartilhavam um mesmo estilo de vida e que desejavam excluir os não-crentes [...] [da interação de seus grupos]." (BENDIX, 1986a, p. 79).

Em resumo, é possível observar ao longo das contribuições de Weber, em A Ética Protestante e o Espírito do Capitalismo, a existência comum de duas características básicas responsáveis por distinguir os protestantes e suas comunidades. A primeira associa-se à maneira como as doutrinas puritanas inculcaram entre os fiéis uma conduta de vida até então particular, em que preocupações com aspectos econômicos e com o sucesso no mundo empreendedor - ambas derivadas de motivações inicialmente religiosas - nos estimularam à adoção de um ethos ascético baseado na autorregulamentação e na sistematização da vida pública e da privada. A segunda, por sua vez, relaciona-se com as redes de relacionamentos - estruturadas, no contexto religioso, por meio das seitas - e com suas características compositivas singulares expressas na combinação simultânea entre parcial coesão interna, por um lado, e certo distanciamento social que caracteriza as interações dos membros de tais agrupamentos em relação a todos os demais, por outro.

Insere-se, na essência dessa reflexão, outra vertente de análise, também de interesse para a presente pesquisa, que compreende a temática do empreendedorismo por meio da investigação de como os atributos de suas redes sociais podem eventualmente influenciar seus desempenhos no contexto profissional, como será visto em detalhes na próxima seção.

\subsection{Perspectiva Contemporânea segundo Granovetter}

Reflexões, ainda que incipientes, sobre o empreendedor como um ator inserido e integrado a uma rede de relacionamentos remontam a autores como Hirschman (1958), Bohannan e Dalton (1968). Contudo, foi a partir dos trabalhos de Granovetter (1973; 1992a), que as proposições sobre o tema ganharam importantes contribuições (VALE; GUIMARÃES, 2010). Insere-se, nas preocupações de Granovetter (1973; 1985; 1983), a temática sobre os laços sociais. Para o autor, os laços podem ser de duas categorias antagônicas: fortes ou fracos. Os laços fortes são constituídos por contatos frequentes e de longa duração entre dois (díades) ou mais indivíduos, constituindo redes ou conjuntos coesos e integrados. Tais laços são capazes de dotar os membros de uma rede de acesso a recursos como solidariedade, confiança e assistência de maneira mais facilitada, fatores que transformam o desempenho desse tipo de ligação único (GRANOVETTER, 1973; 1983).

Já os laços fracos são caracterizados pelos relacionamentos pouco frequentes, formados em ocasiões nas quais os contatos com as díades são, sobretudo, fortuitos ou de curta duração (GRANOVETTER, 1983). Esses contatos, originários de diferentes tipos de redes sociais e empresariais, possibilitam e fornecem recursos que extrapolam aqueles disponíveis nos conjuntos de relacionamentos nos quais um dado indivíduo encontra-se imerso (GRANOVETTER, 1983; HITE, 2005). Granovetter (1973) vislumbra o papel do empreendedor como um agente capaz de 
conectar, via laços fracos, grupos sociais distintos, compostos por diferentes atores - como produtores, vendedores e compradores - que, de outra maneira, permaneceriam desconectados. Dessa forma, o autor (GRANOVETTER, 1973; 1983) termina por defender a força dos laços fracos. Isso porque, por serem capazes de conectar indivíduos em redes estruturalmente distantes, eles possibilitam a difusão e a circulação de diferentes e importantes informações e oportunidades.

Posteriormente, Granovetter (1985; 2009) avança em suas reflexões sobre o papel e a força dos laços sociais, e, pautado na vertente da Nova Sociologia Econômica, aperfeiçoa, por um lado, os conceitos de imersão (embeddedness) - salientando neste a natureza dinâmica e mutuamente interdependente que caracteriza as transações mercantis e as relações sociais (GRANOVETTER, 1985) -, e, por outro, os argumentos sobre o acoplamento e o desacoplamento social. Com estes, projeta luzes para a necessidade de se pesquisar o estágio de vinculação ou de atrelamento das redes de relacionamentos e salienta eventuais conexões das estruturas sociais com fatores determinantes do empreendedorismo bem-sucedido (GRANOVETTER, 2009).

Entre os campos de interesse de Granovetter (2009) situa-se a temática do empreendedorismo étnico. Como observado por Martes e Rodrigues (2004), uma das vertentes de pesquisa sobre redes sociais $e$ empreendedorismo aborda o tema do empreendedor étnico, enfocando indivíduos que desenvolvem atividades empresariais no país para o qual imigraram, voltando seus produtos e serviços, sobretudo, para a comunidade étnica a que pertencem (ALDRICH, 1990; CHAGANTI; GREENE, 2002). Granovetter (2009), ao investigar a criação e o desenvolvimento de peque- nas empresas por coesas populações de imigrantes, salienta como tais empreendedores conseguem um apropriado equilíbrio entre o acoplamento interno $e$ o desacoplamento externo de suas redes de relações. Essa característica, por sua vez, proporciona-lhes, respectivamente, combinação adequada entre dois aspectos considerados fundamentais para a atividade empreendedora bem-sucedida: i) o primeiro, derivado do acoplamento interno, relaciona-se com o que o autor denomina de "solidariedade horizontal", que se trata do desenvolvimento de confiança e de ajuda mútua entre as pessoas, considerada necessária para construir "[...] empreendimentos maiores do que os que são administrados por indivíduos ou famílias [...]" (GRANOVETTER, 2009, p. 247, tradução nossa); ii) o segundo, por sua vez, associa-se com o desacoplamento externo, expresso em certo distanciamento social que caracteriza os relacionamentos dos empreendedores etnicamente acoplados com os demais indivíduos não identificados sob análoga coletividade. Tal distanciamento, responsável por dotar os empreendedores étnicos de certa autonomia e capacidade de iniciativa, demonstra-se, ao mesmo tempo, capaz de impedir a "solidariedade descontrolada", termo cunhado para ilustrar as situações nas quais reivindicações de natureza não econômica sobrecarregam a eficiência de um dado negócio, solapando sua racionalização (GRANOVETTER, 2009).

O Quadro 1, apresentado a seguir, permite ampliar a natureza da presente reflexão. Elaborado com base nas ideias de Granovetter (2009), o quadro expõe e compara as vantagens e as desvantagens dos indivíduos que desenvolvem iniciativas empreendedoras em duas configurações distintas: i) no país de origem e; ii) em países estrangeiros. 


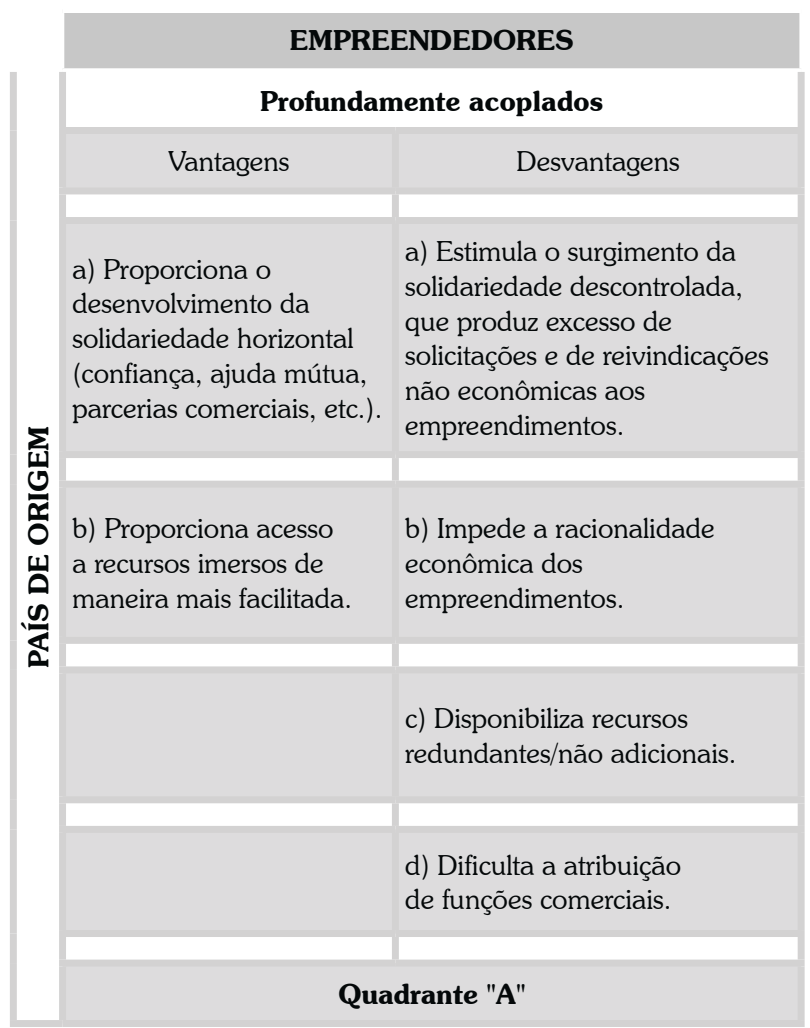

\begin{tabular}{|l|l|}
\multicolumn{1}{|c|}{ EMPREENDEDORES } \\
\multicolumn{1}{|c|}{ Parcialmente acoplados e desacoplados } \\
\multicolumn{1}{|c|}{ Vantagens } \\
\hline $\begin{array}{l}\text { a) Proporciona o } \\
\text { desenvolvimento da } \\
\text { solidariedade horizontal } \\
\text { (confiança, ajuda mútua, } \\
\text { parcerias comerciais, etc.) }\end{array}$ \\
\hline $\begin{array}{l}\text { b) Impede o surgimento da } \\
\text { solidariedade descontrolada }\end{array}$ \\
\hline c) Impulsiona a \\
racionalidade econômica \\
do empreendimento.
\end{tabular}

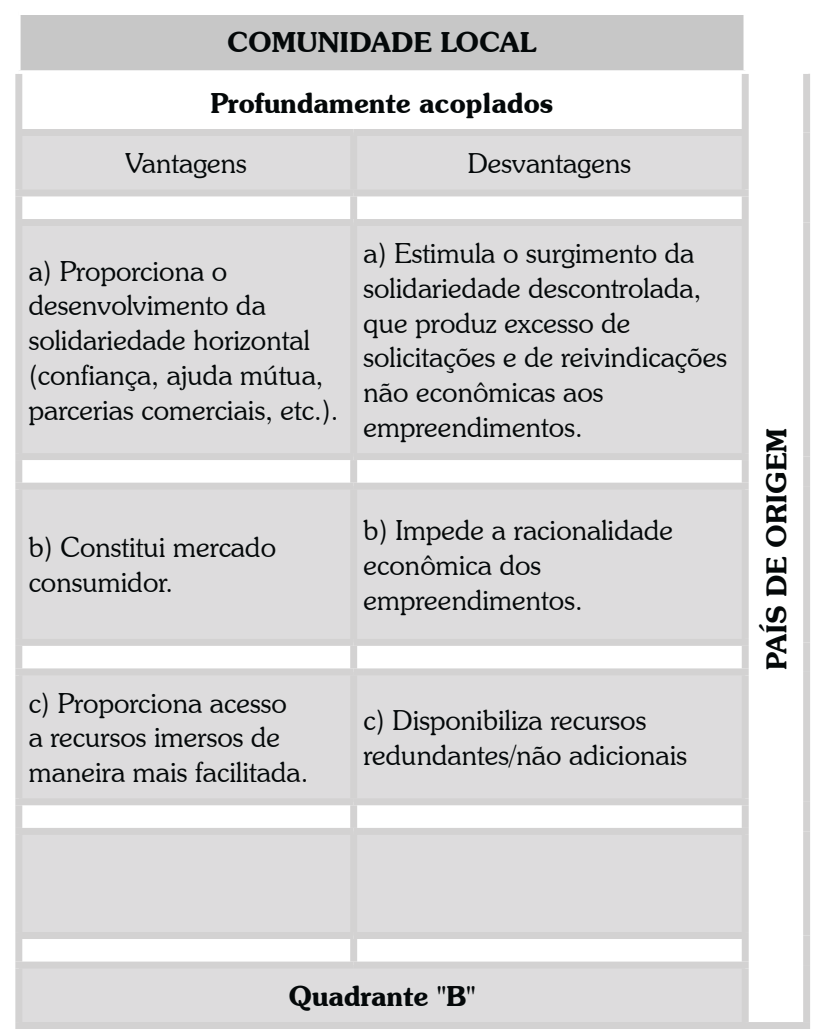

\begin{tabular}{l|l|}
\multicolumn{1}{|c|}{ COMUNIDADE LOCAL } \\
\multicolumn{1}{|c|}{ Parcialmente acoplados e desacoplados } \\
\multicolumn{1}{|c|}{ Vantagens } & \multicolumn{1}{|c|}{ Desvantagens } \\
\hline $\begin{array}{l}\text { a) Proporciona o } \\
\text { desenvolvimento da } \\
\text { solidariedade horizontal } \\
\text { (confiança, ajuda mútua, } \\
\text { parcerias comerciais, etc.). }\end{array}$ \\
\hline $\begin{array}{l}\text { b) Impede o surgimento da } \\
\text { solidariedade descontrolada. }\end{array}$
\end{tabular}

c) Bloqueia as solicitações de natureza não econômicas.

\section{d) Disponibiliza acesso a recursos não redundantes $e$ mutuamente adicionais.}

\section{e) Atenua as expectativas} de generosidade e de bondade em relação aos empreendedores.

f) Possibilita a adoção de práticas competitivas e comerciais mais severas e racionais. 

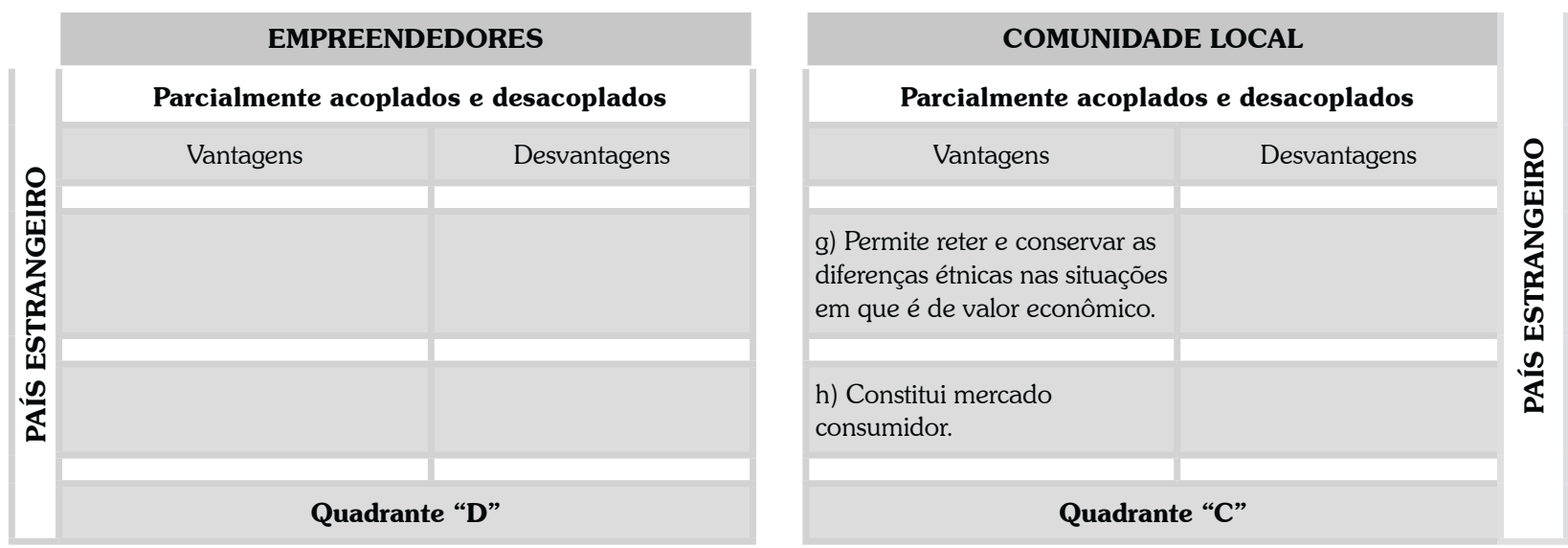

Quadro 1: Vantagens e desvantagens associadas às atividades empreendedoras desenvolvidas no país de origem e em um país estrangeiro

Fonte: Elaborado pelos autores deste artigo

Os quadrantes "A" e "B" apresentam um contexto no qual os indivíduos encontram-se densamente acoplados e ressaltam os recursos eventualmente disponibilizados pelos empreendedores (A) e pelas comunidades $(B)$ aos atores que desenvolvem iniciativas autônomas no próprio país de origem. Já os quadrantes "C" e "D" ilustram um ambiente distinto, no qual os agentes decidem emigrar de suas sociedades nativas para desenvolver atividades profissionais em outro país. Nessa situação, eles encontram-se parcialmente acoplados e desacoplados tanto com os demais empreendedores etnicamente semelhantes (D) quanto com a comunidade local receptora $(\mathrm{C})$.

Note como os empreendedores ilustrados pelos Quadrantes "A" e "B" obtêm acesso facilitado a importantes recursos -como auxílio financeiro, ajuda mútua, apoio emocional, entre outros - derivados do desenvolvimento da solidariedade horizontal com os demais autônomos e com a comunidade na qual estão inseridos. Não obstante, o fato de se encontrarem fortemente acoplados ou integrados à estrutura social nativa proporciona-lhes, ao mesmo tempo, diferentes obstáculos capazes de eventualmente prejudicar a otimização de suas iniciativas empresariais.

Isso porque, argumenta Granovetter (2009), os empreendedores podem sofrer com o excesso de solicitações não econômicas oriundas dos demais empreendedores (Quadrante A) e, também, dos amigos, familiares e conhecidos (Quadrante B) com quem mantêm relacionamentos. É somente quando os indivíduos se desacoplam de suas comunidades nativas e se inserem em um novo país - sustentando nestes suas distinções étnicas - segundo Granovetter (2009), é que eles conseguem obstruir o surgimento da solidariedade descontrolada que em configurações originárias solapa a eficiência econômica de suas organizações.

As reflexões de Granovetter sobre a temática do acoplamento e do desacoplamento social, consideradas fundamentais para a presente investigação, seguem condensadas em algumas proposições apresentadas nas alíneas a seguir:

a) o nível apropriado de acoplamento proporciona o desenvolvimento da solidariedade horizontal;

b) o nível apropriado de desacoplamento desestimula o surgimento da solidariedade descontrolada;

c) o empreendedor necessita se desacoplar de sua comunidade de origem (familiares, amigos próximos, conhecidos) para que possa se libertar das reivindicações não econômicas que impedem o desenvolvimento ótimo de suas iniciativas empreendedoras;

d) somente quando emigram de seus países nativos os empreendedores conseguem, através das diferenças étnicas que possuem com as populações receptoras, solapar a solidariedade descontrolada e embutir eficiência econômica aos seus empreendimentos.

Como visto até o momento, Granovetter (2009) introduz a reflexão sobre o acoplamento e o desacoplamento social com o objetivo de analisar, especificamente, a trajetória de desenvolvimento de um tipo particular de empreendedor: o de natureza fundamentalmente 
étnica. Alguns autores vêm enfocando a temática do acoplamento e desacoplamento em contextos muito particulares, diferentes do enfoque aqui pretendido, a exemplo de Vale e Correa (2015), que propõem o esboço de uma tipologia sobre empreendedores; de Castilla et al. (2010), que buscam analisar algumas dimensões do fenômeno Vale do Silício; de Luo (2011), interessado em analisar algumas dimensões do ambiente dos negócios, na China. Nenhum deles, no entanto, enfoca a temática de interesse do presente artigo.

Acredita-se que é possível, nesse momento, recorrer às proposições teóricas de Granovetter, associando-as às proposições de Weber, de maneira a ampliar a compreensão relativa à dinâmica de outro tipo de empreendedor: o de natureza religiosa, como será demonstrado na seção seguinte.

\subsection{Em Busca de um Modelo Conceitual: integrando Max Weber e Mark Granovetter}

Embora voltados a contextos socioeconômicos e temporais distintos, é possível observar a existência de certas regularidades e semelhanças que caracterizam parte das reflexões de Max Weber, por um lado, e as de Mark Granovetter, por outro. Nesse sentido, observe, primeiramente, como os empreendedores podem, por motivações essencialmente religiosas (Max Weber) ou por de natureza étnica (Mark Granovetter), integrarem ou acoplarem redes sociais eventualmente capazes de fornecerem aos indivíduos-membros diferentes recursos - tais como financeiros, sociais e emocionais - considerados em muitos aspectos fundamentais. Ao mesmo tempo, note como os indivíduos imbricados em agrupamentos religiosos ou étnicos encontram-se parcialmente desintegrados ou desacoplados dos demais atores que, por diferentes motivos, não se demonstram amoldados sob análoga marcação. Essas duas possíveis associações permitem, de uma maneira geral, afirmar que os empreendedores religiosos podem, sob certas circunstâncias, desfrutarem, a exemplo dos empreendedores étnicos, de diferentes recursos que somente o adequado ajuste entre o acoplamento e o desacoplamento de suas estruturas sociais demonstra-se capaz de proporcionar.

O Quadro 2, apresentado a seguir, possibilita ampliar a natureza da presente reflexão. Elaborado a partir das proposições teóricas de Mark Granovetter e de Max Weber, expõe análise comparativa entre os benefícios desfrutados pelos empreendedores étnicos salientados pela abordagem contemporânea (Granovetter, 2009), por um lado, e os atributos extraídos pelos empreendedores religiosos enfatizados pela perspectiva clássica (WEBER, 1996 [1905]), por outro.

Proposições Teóricas

\section{Mark Granovetter (2009)}

Os empreendedores podem, por motivações étnicas, acoplarem-se endogenamente em redes sociais coesas.

Os agrupamentos étnicos proporcionam aos indivíduosmembros recursos eventualmente considerados fundamentais às suas atividades empreendedoras.

Os integrantes das redes identificam-se acoplados sob mesma coletividade, sendo esta de natureza essencialmente étnica e especial.

Os membros das redes étnicas impedem o surgimento

de reivindicações não econômicas por parte dos demais indivíduos não endogenamente acoplados, ou seja, não identificados sob mesma uniformidade.

Aos grupos étnicos, o acoplamento interno disponibiliza recursos endógenos e o desacoplamento externo impede as solicitações descontroladas.

\section{Max Weber (1996 [1905])}

Os indivíduos podem, por motivações religiosas, acoplarem-se endogenamente em redes sociais coesas.

Os agrupamentos religiosos proporcionam aos

indivíduos-membros recursos eventualmente considerados fundamentais às suas atividades empreendedoras.

Os membros das redes identificam-se acoplados sob mesma coletividade, sendo esta de natureza essencialmente religiosa.

Os membros das estruturas religiosas impedem o surgimento de reivindicações não econômicas por parte dos demais indivíduos não endogenamente acoplados, ou seja, não identificados sob mesma uniformidade.

Aos agrupamentos religiosos, o acoplamento interno disponibiliza recursos endógenos e o desacoplamento externo impede as solicitações descontroladas.

Quadro 2: Síntese das principais proposições teóricas e seus respectivos autores de interesse.

Fonte: Elaborado pelos autores deste artigo 
Observe como a associação entre as abordagens teóricas de Max Weber e as de Mark Granovetter permite elevar as reflexões sobre os conceitos de acoplamento e de desacoplamento a novo patamar. Atualmente dedicados à compreensão e à análise da dinâmica empreendedora de natureza exclusivamente étnica, esses argumentos podem, possivelmente, demonstrarem-se úteis para ampliar o entendimento, também, das iniciativas inseridas no segmento empreendedor religioso, ainda hoje pouco investigado na academia brasileira.

Mas, há algo mais aí, chamando a atenção ainda para distinta constatação de considerável relevância teórica. Diferentemente de Granovetter (2009), que observa o deslocamento de indivíduos de suas comunidades nativas (país de origem) para, a partir daí, em outro país, poderem desfrutar dos benefícios de um adequado ajuste entre o acoplamento interno $e o$ desacoplamento externo -, os empreendedores religiosos - aqui enfatizados - não precisariam mover-se de seus países de origem. Ou seja, não necessitariam promover mudança espacial radical.

Isso porque, nesses contextos religiosos, salientam alguns pesquisadores da área de sociologia no Brasil (CAMARGO, 1973; PIERUCCI; PRANDI, 1987, 1996; PRANDI, 1996, 1999, 2008; ALMEIDA, 2006; PACHECO; RIBEIRO DA SILVA; RIBEIRO, 2007; GRACINO JUNIOR, 2008; HERVIEU-LÉGER, 2008; TEIXEIRA, 2008; ISAIA, 2009; MARIANO, 2013; OLIVEIRA, 2009; PASSOS; ZORZAN; ROCHA, 2011; PIERUCCI, 2000a; 2004a; 2004b; 2005; 2006a; 2006b; 2011), o que se verifica, muitas vezes, é a ocorrência de um deslocamento de um grupo social para outro. Nesse sentido, bastaria aos empreendedores desacoplarem-se de seus agrupamentos sociais e religiosos adscritos, $e$, em seguida, acoplarem-se em novas redes de natureza protestante, para que eles possam eventualmente desfrutar da racionalidade econômica que tais estruturas eclesiásticas evangélicas possibilitam ao desenvolvimento de suas iniciativas profissionais.
Essa seria, inclusive, a situação que possivelmente caracterizaria a trajetória de muitos dos empreendedores religiosos atualmente em crescimento no país. Anteriormente acoplados a redes eclesiásticas derivadas, em grande parte, de uma tradição familiar principalmente católica, tais indivíduos encontrariam na conversão religiosa a possibilidade de adesão a novos grupos sociais de natureza, maiormente, protestante. Nestes, "[...] é interessante notar [como], não poucas vezes, a nova 'família' da comunidade pentecostal se sobressai como objeto de investimento de tempo e de afeto em relação à família natural." (PACHECO; RIBEIRO DA SILVA; RIBEIRO, 2007, p. 58).

Mesmo a aversão apresentada por parte dos filhos à intensa dedicação religiosa de suas mães, por exemplo, demonstra-se comumente ineficiente em sua meta de desestimula-las a frequentarem regularmente a igreja. Nesses contextos, é bastante comum "[...] maridos [serem] obrigados a aceitar, pais [serem] surpreendidos pelos novos referenciais de seus filhos $e$ amigos se [ressentirem] por terem sido deixados de lado" (PACHECO, RIBEIRO DA SILVA; RIBEIRO, 2007, p. 58). Evidências claras de como a "[...] conversão pentecostal reordena o relacionamento com o outro" (PACHECO; RIBEIRO DA SILVA; RIBEIRO, 2007, p. 58), e de como a "[...] religião aproxima os iguais e os distancia dos outros." (PRANDI, 2008, p. 159).

A partir das reflexões apresentadas até o momento, é possível observar a existência de duas concepções teóricas distintas. A primeira, já consolidada, é baseada na perspectiva contemporânea derivada especificamente das reflexões de Mark Granovetter sobre o empreendedorismo étnico. A segunda, por sua vez, é totalmente inédita e propõe, das junções teóricas entre Max Weber e Mark Granovetter, quadro conceitual baseado em visão teórica proporcionalmente ampliada. A Figura 1 apresentada a seguir permite ilustrar com mais detalhes a natureza da presente linha de raciocínio. 


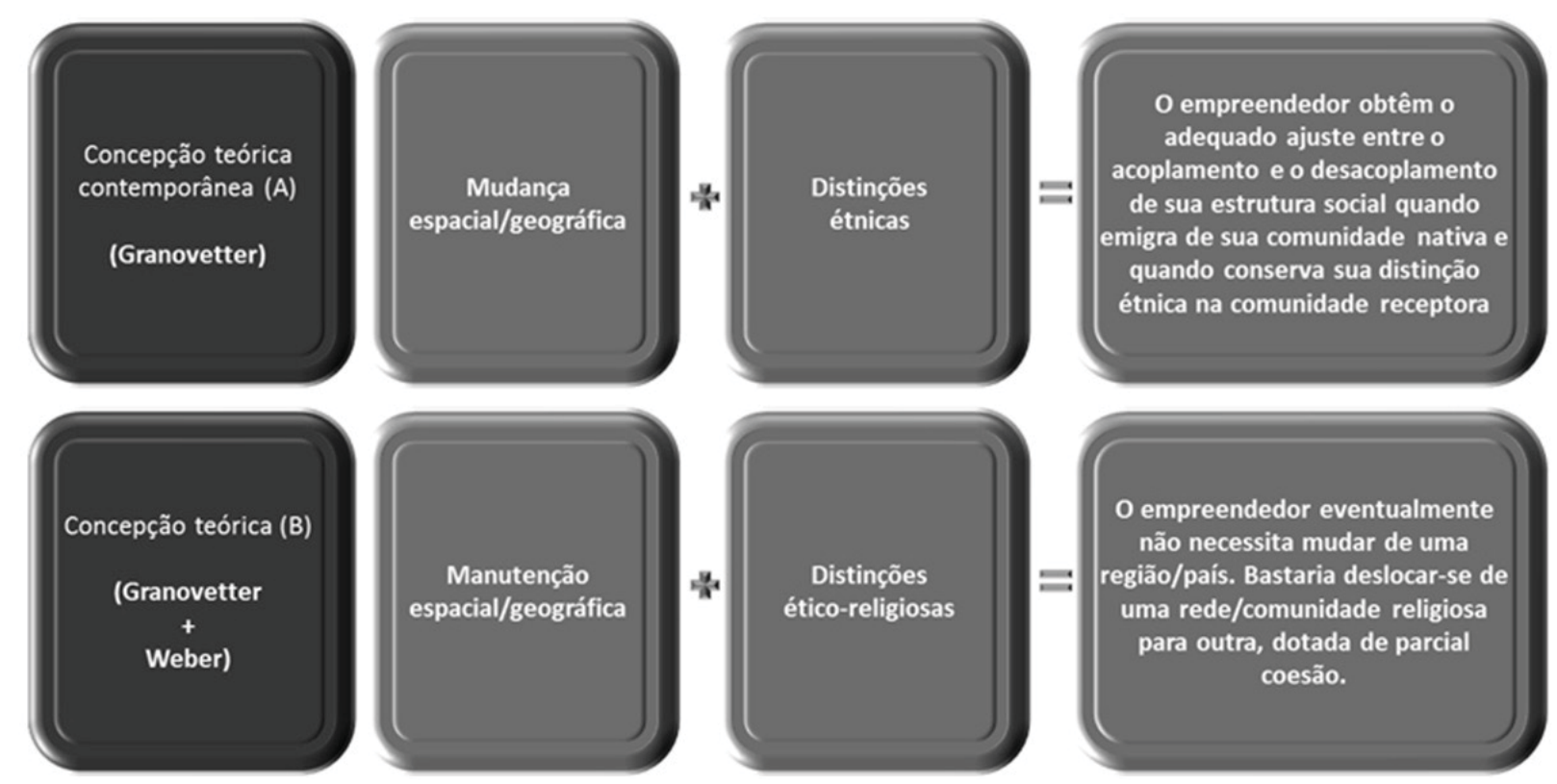

Figura 1: As diferentes visões sobre os requisitos básicos necessários ao desenvolvimento de empreendedores acoplados em agrupamentos sociais

Fonte: Elaborada pelos autores deste artigo

Enquanto a primeira concepção (A) enfatiza a importância de um deslocamento espacial (mudança de um país para outro), a segunda (B) sugere que uma conversão religiosa pode ser suficiente, para, eventualmente, garantir um equilíbrio adequado entre acoplamento e desacoplamento. Essa segunda concepção, como já observado, deriva das reflexões teóricas de Max Weber sobre as comunidades protestantes e suas características compositivas singulares expressas em suas capacidades de congregar elementos de coesão interna e de isolamento ou de retração social, associadas, ao mesmo tempo, às postulações contemporâneas de Mark Granovetter relacionadas à temática sobre o acoplamento e o desacoplamento das comunidades de empreendedores imigrantes.

Nesta nova concepção, os empreendedores podem, por motivações essencialmente religiosas, integrarem estruturas sociais coesas e eventualmente minoritárias e desfrutarem, a exemplo dos empreendedores emigrantes: i) de diferentes benefícios derivados de suas acopladas redes de relacionamentos e; ii) da racionalidade de seus empreendimentos, possibilitada, em grande parte, pela ausência de reivindicações não econômicas oriundas de indivíduos não identificados sob mesma coletividade, sendo esta especificamente religiosa. Além disso, os empreendedores não precisam mudar de sua comunidade de origem para que possam desfrutar de diferentes recursos (solidariedade mútua e ausência de reivindicações não econômicas) que apenas o apropriado ajuste entre o acoplamento e o desacoplamento social demonstra-se capaz de proporcionar.

\section{Considerações Finais}

As proposições teóricas suscitadas neste trabalho sinalizam a relevância da presente pesquisa. Cada um dos temas aqui ressaltados - por um lado, a reflexão sobre o acoplamento e o desacoplamento social - hoje reservada a adstrito campo de estudos sobre as redes sociais -, e, por outro lado, o desenvolvimento de empreendedores de natureza essencialmente religiosa - atualmente pouco investigado no Brasil - traz, eventualmente, sua própria contribuição à academia.

Observa-se que, de maneira semelhante ao caso do empreendedor étnico, abordado por Granovetter (2002), que se muda de uma comunidade de origem para outra (de um país para outro), libertando-se de excesso de laços fortes e suas inibições; o indivíduo criado em uma comunidade católica, que se torna pastor evangélico, deixa sua comunidade de origem e cria novos vínculos em outra comunidade, onde vai prosperar como um novo líder religioso (empreende- 
dor religioso). Assim procedendo, parece ser capaz não apenas de criar novas relações, baseadas em confiança e dotadas de algum nível de solidariedade; mas também, tornar-se mais invulnerável a eventuais pressões advindas por parte de antigos familiares ou amigos (laços fortes) no sentido de inibi-lo no processo de engajamento na nova religião/ igreja.

Observa-se também que, à semelhança do empreendedor étnico (MARTES; RODRIGUES, 2002), o empreendedor religioso: i) também deixou sua comunidade de origem (no caso, não um local geográfico, mas uma comunidade baseada em uma religião de origem); ii) também inseriu-se em uma nova comunidade (religiosa), onde interage com atores dotados da mesma religião ou pertencentes a uma mesma igreja.

De maneira similar ao empreendedor étnico (MARTES; RODRIGUES, 2002), também desenvolve seus esforços empreendedores no interior da nova comunidade (ALDRICH, 1990; CHAGANTI; GREENE, 2002), não apenas ao direcionar os serviços de sua igreja, exclusivamente para sua comunidade religiosa, como, também e sobretudo, interagindo no dia a dia, especialmente, com membros dessa nova comunidade. Observa-se, aqui, como a associação entre as duas temáticas, tal como proposta neste trabalho, permite avançar em direção a novos desdobramentos teóricos e a possíveis implicações de natureza prática.

Contudo, não fez parte do conteúdo do presente artigo, avançar nessas possíveis implicações de natureza mais prática, por mais ricas e interessantes que essas possam, a primeira vista, parecer. Diferentes pesquisas empíricas deverão ser executadas, visando o teste definitivo e a adequação do modelo teórico aqui esboçado. Para isso, sugere-se a realização de pesquisas envolvendo diferentes indivíduos convertidos a nova religião, que se tornaram pastores evangélicos, tanto em pequenas igrejas de periferia, quanto em grandes empreendimentos religiosos.

Tais iniciativas certamente possibilitariam robustecer os argumentos sobre o acoplamento e o desacoplamento das estruturas sociais no contexto do empreendedorismo religioso. Como sugerido, a análise da temática do acoplamento/desacoplamento, no contexto enfocado, poderia ampliar, consideravelmente, a utilização desse aparato teórico. Ao mesmo tempo, seria possível expandir o entendimento da dinâmica envolvida no desenvolvimento do empreendedor religioso, atualmente em franca expansão no país (GRACINO JUNIOR, 2008; HERVIEU-LÉGER, 2008; MARIANO, 2003, 2008, 2013; MARTES; RODRIGUES, 2004; PIERUCCI, 1999, 2008, 2011; PRANDI, 1996, 1999, 2008; SERAFIM, MARTES, RODRIGUES, 2012).

Nesse sentido, as inferências teóricas aqui realizadas se limitam a funcionar como um estímulo para construções e análises empíricas mais amplas e variadas sobre o fenômeno do empreendedorismo religioso associado às análises contemporâneas derivadas dos estudos das redes sociais.

\section{ReferêNCIAS}

ALDRICH, H.; ZIMMER. Entrepreneurship through social networks. In: SEXTON, R. Smilor (Org.). The Art and science of entrepreneurship in a global context. New York: Routledge, 1986. p. 3-23.

ALDRICH, H. E.; WALDINGER, R. Ethnicity and Entrepreneurship. Annual Review of Sociology, [S.l.], n. 16 , p. $111-36,1990$

ALMEIDA, R. A expansão pentecostal: circulação e flexibilidade. In: TEIXEIRA, F; MENEZES, R. (Org.). As religiões no Brasil: continuidades e rupturas. Petrópolis: Vozes, 2006. p. 111-122.

BAECHLER, J. Religião. In: BOUNDON, R. Tratado de Sociologia. Rio de Janeiro: Jorge Zahar, 1995. p. 449488.

BENDIX, R. Max Weber, um perfil Intelectual. Brasília, DF: Editora da UNB, 1986a.

BENDIX, R. Max Weber, um perfil Intelectual. Brasília, DF: Editora da UNB, 1986b.

BIRLEY, S. The role of networks in the entrepreneurial process. Journal of Business Venturing, [S.I.], v. 1, n. 1, p. 107-117, 1986.

BOHANNAN, P.; DALTON, G. Markets in Africa.

Evanston: Northwestern University Press, 1968.

BURT, R. S. Models of Network Structure. Annual Review of Sociology, [S.l.], n. 6, p. 79-141, 1980. Disponível em: <http://www.annualreviews.org/doi/abs/10.1146/annurev. so.06.080180.000455>. Acesso em: 15 jan. 2016. 
BURT, R. S. The Social Capital of Opinion Leaders. Annals of the American Academy of Political and Social Science, [S.l.], v. 566, n. 1, p. 37-54, 1999.

BURT, R. S. Information and structural holes: comment on Reagans and Zuckerman. Industrial and Corporate Change, [S.l.], v. 17, n. 5, p. 953-969, 2008. Disponível em: <http://icc.oxfordjournals.org/content/17/5/953. short>. Acesso em: 10 jan. 2016.

CAMARGO, C. P. F. Católicos, protestantes, espíritas. Petrópolis: Vozes, 1973.

CASTILLA, E. J. et al. Social networks in Silicon Valley. 2010. Disponível em: <http://www.stanford.edu/ group/esrg/siliconvalley/docs/siliconvalleyedge.pdf $>$. Acesso em: 15 out. 2015.

CHAGANTI, R.; GREENE, P. G. Who Are Ethnic Entrepreneurs? A Study of Entrepreneurs' Ethnic Involvement and Business Characteristics. Journal of Small Business Management, [S.l.], v. 40, n. 2, p. 126143, 2002.

CHELL, E. Networking entrepreneurship and microbusiness behavior. Entrepreneurship and

Regional Development, [S.l.], n. 12, p. 195-214, 2000.

COHN, G. Max Weber: sociologia. São Paulo: Ática, 1999

CORREA, V. S.; VALE, G. M. V. Ação Econômica e

Religião: igrejas como empreendimentos no Brasil.

Revista de Administração Contemporânea, Rio de Janeiro, ahead of print, p. 1-18, agosto 2016. Disponível em: <http://www.anpad.org.br/periodicos/arq_pdf/ ahead_46.pdf $>$. Acesso em: 20 jul. 2016.

FINKE, R. The Consequences of Religious Competition: supply-side explanations for religious change. In: YOUNG, L. A. (Ed.). Rational Choice Theory and Religion. Routledge, p. 45-63, 1997. Disponível em: <http://books. google.ca/books?id=4dMzunjcz4QC\&printsec $=$ frontcover $\& \mathrm{hl}=\mathrm{pt}-\mathrm{BR} \&$ source $=\mathrm{gbs} \_\mathrm{ge} \_$summary_r\&cad $=0 \# \mathrm{v}=$ one page \&q\&f=true $>$. Acesso em: 9 out. 2015.

FREUND, J. Max Weber e a Ética Protestante e o Espírito de Capitalismo. O Estado de São Paulo, São Paulo, Caderno de Programas e Leituras, 1983.

FREUND, J. Sociologia de Max Weber. Rio de Janeiro: Forense Universitária, 1987a.
FRIGERIO, A. O paradigma da escolha racional: mercado regulado e pluralismo religioso. Tempo Social, Revista de Sociologia da USP, São Paulo, v. 20, n. 2, p. 17-39, 2008. Disponível em: <http://www.revistas.usp.br/ts/ article/view/12577> . Acesso em: 28 out. 2015.

GRACINO JUNIOR, P. Dos interesses weberianos dos sociólogos da religião: um olhar perspectivo sobre as interpretações do pentecostalismo no Brasil. Horizonte, [S.l.], v. 6, n. 12, p. 69-92, 2008. Disponível em: < http:// periodicos.pucminas.br/index.php/horizonte/article/ view/440>. Acesso em: 25 jan. 2015.

GRANOVETTER, M. The strength of weak ties. American Journal of Sociology, [S.l.], v. 78, n. 6, p. 1.360-1.380, 1973.

GRANOVETTER, M. The strength of weak ties: a network theory revisited. Sociological Theory, [S.l.], n. 1, p. 201233, 1983.

GRANOVETTER, M. Economic action and social structure: the problem of embeddedness. American Journal of Sociology, [S.l.], v. 91, n. 3, p. 481-510, 1985.

GRANOVETTER, M. The Sociological and Economic Approaches to Labor Market Analysis: a social structural view. In: FARKAS, G. Industries, firms, and jobs: sociological and economic approaches. Plenum Press: New York, 1988. p. 187-216.

GRANOVETTER, M. The Myth of Social Network Analysis as a Special Method in the Social Sciences. Connections, [S.l.], v. 13, n. 1, p. 13-16, 1990.

GRANOVETTER, M. Economic Institutions as Social Constructions: a framework for analysis. Acta Sociologica, [S.l.], v. 35, n. 1, p. 3-11, 1992a. Disponível em: <http://www.jstor.org/stable/4194749>. Acesso em: 19 jun. 2015.

GRANOVETTER, M. Problems of Explanation in Economic Sociology. In: NOHRIA, N.; ECCLES, R. G.

Networks and organizations: structure, form, and action. Harvard Business School Press, 1992b. p. 25-55.

GRANOVETTER, M. Business Groups and Social Organization. In: SMELSER, N. J.; SWEDBERG, R.

The Handbook of Economic Sociology. Princeton University Press: New York, 2005a. p. 429-450. 
GRANOVETTER, M. The Impact of Social Structure on Economic Outcomes. Journal of Economic Perspectives, [S.l.], v. 19, n. 1, p. 33-50, $2005 b$.

GRANOVETTER, M. The Economic Sociology of Firms and Entrepreneurs. In: SWEDBERG, R.

Entrepreneurship: the social science view. Oxford University Press: New York, 2009. p. 244-275.

HERVIEU-LÉGER. O peregrino e o convertido: a religião em movimento. Petrópolis: Vozes, 2008.

HIRSCHMAN, A. O. The Strategy of Economic Development. Connecticut: Yale, 1958.

HITE, J. M. Evolutionary processes and paths of relationally embedded network ties in emerging entrepreneurial firms. Entrepreneurship Theory and Practice, [S.I.], n. 29, p. 113-143, 2005.

IANNACCONE, L. Voodoo Economics? Reviewing the Rational Choice Approach to Religion. Journal for the Scientific Study of Religion, [S.l.], v. 34, n. 1, p. 76-88, 1995.

IANNACCONE, L. Rational Choice: framework for the scientific study of religion. In: YOUNG, L. A. (Ed.).

Rational Choice Theory and Religion, Routledge, 1997. p. 25-44. Disponível em: <http://books.google.ca/ books?id=4dMzunjcz4QC\&printsec $=$ frontcover\&hl=ptBR\&source $=$ gbs_ge_summary_r\&cad $=0 \# \mathrm{v}=$ onepage $\& \mathrm{q}$ $\& \mathrm{f}=$ true $>$. Acesso em: 26 out. 2015.

ISAIA, A. C. O campo religioso brasileiro e suas transformações históricas. Revista Brasileira de História das Religióes, [S.l.], n. 3, p. 95-105, 2009. Disponível em: <http://www.dhi.uem.br/gtreligiao/pdf2/ texto\%206.pdf>. Acesso em: 10 jan. 2016.

JOHANISSON, B. Networking and entrepreneurial growth. In: SEXTON, D.; LANDSTRON, H. Handbook of entrepreneurship. London: Blakwell, 2000. p. 368-386.

KALBERG, S. Max Weber: uma introdução. Rio de Janeiro: Zahar, 2010.

LECHNER, C.; DOWLING, M.; WELPE, I. Firm networks and firm development: the role of the relational mix. Journal of Business Venturing, [S.I.], v. 14, n. 1, p. 514-540, 2006.
LUO, J. D. Guanxi revisited: An exploratory study of familiar ties in a Chinese workplace. Management and Organization Review, [S.1.], v. 7, n. 2, p. 329-351, 2011.

MARIANO, R. Efeitos da secularização do Estado, do pluralismo e do mercado religiosos sobre as igrejas pentecostais. Civitas - Revista de Ciências Sociais, [S.l.], v. 3, n. 1, p. 111-125, 2003. Disponível em: <http:// revistaseletronicas.pucrs.br/ojs/index.php/civitas/article/ view/112>. Acesso em: 14 out. 2015.

MARIANO, R. Usos e limites da teoria da escolha racional da religião. Tempo Social, Revista de Sociologia da USP, São Paulo, v. 20, n. 2, p. 41-66, 2008. Disponível em: <http://www.scielo.br/scielo.php?pid=S0103$20702008000200003 \&$ script $=$ sci_arttext $>$. Acesso em: 15 jun. 2015.

MARIANO, Ricardo. Antônio Flávio Pierucci: sociólogo materialista da religião. Revista Brasileira de Ciências Sociais, [S.l.], v. 28, n. 8, p. 7-16, 2013. Disponível em: <http://www.scielo.br/scielo.php?pid=S0102$69092013000100001 \&$ script $=$ sci_arttext $>$. Acesso em: 3 maio 2015.

MARTES, A. C. B. Redes e sociologia econômica. São Paulo: RAE publicações, 2009.

MARTINELLI, A. Contexto do empreendedorismo. In: MARTES, A. C. B. Redes e sociologia econômica. São Paulo: RAE publicações, 2009.

NERI, M. C.; CARVALHAES, L.; MONTE, S. R. S. Novo Mapa das Religiões: relatório de Pesquisa, 2011. São Paulo, SP: Centro de Políticas Sociais, Fundação Getúlio Vargas, 2011.

OLIVEIRA, A. S. de. Desvendando a religião e as religiões mundiais em Max Weber. Horizonte, [S.I.], v. 7, n. 14, p. 136-155, 2009. Disponível em: <http://periodicos. pucminas.br/index.php/horizonte/article/view/P.21755841.2009v7n14p136>. Acesso em: 12 fev. 2015.

PACHECO, E. T.; RIBEIRO DA SILVA, S.; RIBEIRO, R. G. Eu era do mundo: transformações do auto-conceito na conversão pentecostal. Psicologia: Teoria e Pesquisa, [S.l.], v. 24, n. 1, p. 53-62, 2007. Disponível em: < http:// www.scielo.br/scielo.php?script =sci_arttext\&pid $=$ S0102$37722007000100007 \& \operatorname{lng}=\mathrm{pt} \& \mathrm{nrm}=\mathrm{iso} \&$ userID $=-2>$. Acesso em: 22 maio 2015. 
PASSOS, M.; ZORZON, P. L. G.; ROCHA, D. O que (não) dizem os números - para além das estatísticas sobre o "Novo Mapa das Religiões Brasileiro". Horizonte, [S.I.], v. 9, n. 23, p. 690-714, 2011. Disponível em: <http:// periodicos.pucminas.br/index.php/horizonte/article/view/ P.2175-5841.2011v9n23p690 > . Acesso em: 30 set. 2015.

PIERUCCI, A. F. Apêndice: As religiões no Brasil. In: GAARDER, J.; HELLERN, V.; NOTAKER, H. O Livro das Religióes. São Paulo: Companhia das Letras, 2000a. p. 281-302.

PIERUCCI, A. F. Secularização segundo Max Weber: da contemporânea serventia de voltarmos a acessar um velho sentido. In: SOUZA, J. (Org.). A atualidade de Max Weber. Brasília, DF: Editora da UNB, 2000b. p. 105-162.

PIERUCCI, A. F. "Bye bye, Brasil" - o declínio das religiões tradicionais no Censo 2000. Estudos Avançados, [S.l.], v. 18, n. 52, p. 17-28, 2004a. Disponível em: $<$ http://www.scielo.br/scielo.php?script=sci_arttext\&pid $=$ S0103-40142004000300003 $>$. Acesso em: 15 jul. 2015 .

PIERUCCI, A. F. Secularização e declínio do catolicismo. In: SOUZA, B. M. de.; MARTINHO, L. M. S. (Org.).

Sociologia da religião e mudança social: católicos, protestantes e novos movimentos religiosos no Brasil. São Paulo: Paulus, 2004b. p. 13-21.

PIERUCCI, A. F. O retrovisor polonês. Folha de São Paulo, São Paulo, Caderno "Mais". 2005. Disponível em: <http://www1.folha.uol.com.br/fsp/mais/fs1004200504. htm >. Acesso em: 22 set. 2015.

PIERUCCI, A. F. Ciências sociais e religião - A religião como ruptura. In: TEIXEIRA, F.; MENEZES, R. (Org.). As religióes no Brasil: continuidades e rupturas. Petrópolis: Vozes, 2006a. p. 17-34.

PIERUCCI, A. F. Religião como solvente - uma aula. Novos Estudos - CEBRAP, [S.l.], n. 75, p. 111-127, $2006 \mathrm{~b}$.

Disponível em: <http://www.scielo.br/scielo.php?script=sci arttext\&pid=S0101-33002006000200008 > . Acesso em: 14 ago. 2015.

PIERUCCI, A. F. Religiões no Brasil. In: BOTELHO, A.; SCHWARCZ, L. M. (Org.). Agenda Brasileira: temas de uma sociedade em mudança. São Paulo: Companhia das Letras, 2011. p. 470-479.
PIERUCCI, A. F; PRANDI, R. Assim como não era no princípio. Religião e ruptura na obra de Procópio Camargo. Novos Estudos - CEBRAP, [S.l.], n. 17, p. 29-35, 1987. Disponível em: <http://www.novosestudos. com.br/v1/files/uploads/contents/51/20080623_assim_ como_era.pdf>. Acesso em: 30 mar. 2015.

\section{PIERUCCI, A. F.; PRANDI, R. A realidade social das} religióes no Brasil. São Paulo: Hucitec, 1996.

PRANDI, R. Religião Paga, Conversão e Serviço. Novos Estudos - CEBRAP, [S.l.], n. 45, p. 65-77, 1996.

Disponível em: <http://www.novosestudos.com.br/v1/ contents/view/718 > . Acesso em: 15 ago. 2015.

PRANDI, R. Religião não é mais herança, mas opção.

Folha de São Paulo, São Paulo, Caderno Especial, 1999. Disponível em: <http://www1.folha.uol.com.br/fsp/ especial/fe/fe06.htm >. Acesso em: 16 ago. 2015.

PRANDI, R. Converter indivíduos, mudar culturas. Tempo Social, Revista de Sociologia da USP, São Paulo, v. 20, n. 2, p. 155-172, 2008. Disponível em: <http://www. revistas.usp.br/ts/article/view/12583 > . Acesso em: 12 jan. 2015

RABUSKE, I. J. et al. Evangélicos brasileiros: quem são, de onde vieram e no que acreditam? Revista Brasileira de História das Religióes, [S.I.], v. 4, n. 12, p. 255-267, 2012. Disponível em: <http://www.journaldatabase.org/ articles/evangelicos_brasileiros_quem_sao_onde.html $>$. Acesso em: 19 mar. 2015.

SCHLUCTHER, W. A origem do modo de vida burguês. In: SOUZA, J. (Org.). O Malandro e o Protestante: a tese weberiana $e$ a singularidade cultural brasileira. Brasília: Editora da UNB, 1999. p. 121-136.

\section{SELL, C. E. Sociologia clássica: Durkheim, Weber e}

Marx. Itajaí: Univali, 2004. p. 93-142.

SERAFIM, M. C.; MARTES, A. C. B.; RODRIGUES, C. L. Segurando na mão de Deus: organizações religiosas e apoio ao empreendedorismo. Revista de Administração de Empresas, [S.I.], v. 52, n. 2, p. 217-231, 2012. Disponível em: <http://rae.fgv.br/sites/rae.fgv.br/files/ artigos/10.1590_s0034-75902012000200008_0.pdf > . Acesso em: 15 fev. 2015. 
SOUZA, J. O Malandro e o Protestante: a tese weberiana e a singularidade cultural brasileira. Brasília, DF: Editora da UNB, 1999.

STARK, R. Micro Foundations of Religion: a revised theory. Sociological Theory, [S.1.], v. 17, n. 3, p. 264289, 1999. Disponível em: <http://onlinelibrary.wiley. com/doi/10.1111/0735-2751.00080/abstract >. Acesso em: 25 fev. 2015.

STARK. R.; IANNACCONE, L. R.; FINKE, R. Religion, Science, and Rationality. The American Economic Review, [S.l.], v. 86, n. 2, p. 433-437, 1996. Disponível em: <http://www.jstor.org/discover/10.2307/2118165? uid $=3737664 \&$ uid $=2129 \&$ uid $=2 \&$ uid $=70 \&$ uid $=4 \& \mathrm{~s}$ $\mathrm{id}=21102277811757>$. Acesso em: 19 mar. 2016.

TEIXEIRA, F. Apresentação. In: HERVIEU-LÉGER, D. $O$ peregrino e o convertido: a religião em movimento. Petrópolis: Vozes, 2008. p. 7-13.

UZZI, B. Small Social Structure and Competition in Interfirm Networks: The Paradox of Embeddedness.

Administrative Science Quarterly, [S.l.], v. 42, n. 1, p. 35-67, 1997.

VALE, G. M. V.; GUIMARAES, L. Oliveira. Redes sociais na criação e mortalidade de empresas. Revista de

Administração de Empresas - Eletrônica, [S.l.], v. 50, n. 3, 2010 .

VALE, G, M.; CORREA, V. S. Estrutura social e criação de empresas. Revista de Administração, [S.l.], v. 50, n. 4, p. 432-446, 2015. Disponível em: <http://www.scielo.br/ scielo.php?script $=$ sci_arttext $\&$ pid $=S 0080>$. Acesso em: 12 set. 2016.

WARNER, R. S. Work in Progress Toward a New Paradigm for the Sociological Study of Religion in the United States. American Journal of Sociology, [S.l.], v. 98, n. 5, p. 1.044-1.093, 1993. Disponível em: <http:// www.jstor.org/discover/10.2307/2781583?uid =2129\&ui $\mathrm{d}=2 \&$ uid $=70 \&$ uid $=4 \&$ sid $=21102268560937>$. Acesso em: 24 abr. 2015.

\section{WEBER, M. A Ética Protestante e o espírito do}

capitalismo. 11. ed. São Paulo: Livraria Pioneira Editora, 1996.

WHIMSTER, S. Weber: introdução. Porto Alegre: Artmed, 2009. 